\title{
PRIMARY OSTEOGENIC SARCOMA OF ZYGOMATIC ARCH: A CASE REPORT, WITH WORLD LITERATURE REVIEW
}

Vijaya Kamble ${ }^{1}$ Kajal Mitra², Chetana Ratnaparkhi³, Akshay Kapila ${ }^{4}$

\section{HOW TO CITE THIS ARTICLE:}

Vijaya Kamble, Kajal Mitra, Chetana Ratnaparkhi, Akshay Kapila. "Primary Osteogenic Sarcoma of Zygomatic Arch: A Case Report, with World Literature Review". Journal of Evolution of Medical and Dental Sciences 2014; Vol. 3, Issue 36, August 18; Page: 9494-9499, DOI: 10.14260/jemds/2014/3226

ABSTRACT: We report a rare case of osteogenic sarcoma of zygomatic arch presenting in a 20 year old male patient and a review of world literature on incidence and imaging. Craniofacial osteosarcomas are rare primary malignant bone tumours. This paper presents a case of osteogenic sarcoma of left zygomatic arch, showing erosion of middle aspect of left zygomatic arch with sun-ray spicules noted perpendicular to the cortex with multiple conglomerated new bone formation and associated soft tissue swelling extending inferiorly into the left infratemporal fossa and later diagnosed as osteosarcoma with chondroblastic differentiation. In head and neck, the most common sites of origin are the mandible, maxilla, nasal septum, hard palate and skull vault. More than $50 \%$ of craniofascial osteosarcomas arise in the jaw. Mandible is more commonly affected than maxilla. Zygomatic arch is a very rare site of involvement. Osteosarcoma should be considered in the differential diagnosis of lytic lesions with associated soft tissue swelling of zygomatic arch. Only four cases of primary osteogenic sarcoma of zygomatic arch have been reported in the English- language literature.

KEYWORDS: Primary Osteogenic sarcoma, zygomatic arch, computed tomography.

CASE REPORT: A 20 year old man sustained trivial trauma in the left malar region thereafter he noticed some swelling in the same region about 2 months back. It was painless swelling and increased in size within 2 months. On local examination, a 7x $6 \mathrm{~cm}$ hard, non-tender, non-mobile swelling was present in the left malar region extending upto the left preauricular region. Cranial nerve examination was normal with no ophthalmoplegia or visual changes. There was no clinical evidence of intraoribital or intracranial extension.

Computed tomography scan (CT Scan) revealed osteolytic areas with erosion of middle part of left zygomatic arch on its medial and lateral aspects with subtle cortical discontinuity at places in this part of zygomatic arch. Wide zone of transition is noted. Areas of new bone formation representing the osteoid matrix, with a large soft tissue component surrounding the left zygomatic arch and extending inferiorly into left infratemporal fossa were noted. The medullary cavity of this part of the zygomatic bone showed soft tissue density within, suggestive of marrow infiltration (Figure 1 and Figure 2). Periosteal reaction is not appreciated. The soft tissue swelling was seen abutting the superficial lobe of left parotid gland.

Osteogenic sarcoma and Ewing's sarcoma were considered in differential diagnosis considering the age, presentation and imaging features. Later on CT Scan of Chest was done to rule out any lung metastasis. The study was negative. True-cut biopsy of the lesion revealed features of osteosarcoma with predominant chondroblastic differentiation. Chest radiograph, hemogram and liver function tests were normal. The patient was taken up for surgery and a radical excision of tumour along with left zygomatic arch with lateral tarsorraphy done. 
He completed six cycles of chemotherapy. Histopathology of the excised lesion revealed osteogenic sarcoma with predominant chondroblastic differentiation.

DISCUSSION: Osteosarcomas are commonly seen in the appendicular skeleton. It is a malignant bone tumor arising from primitive bone forming mesenchyme. Craniofacial osteosarcomas are rare primary malignant bone tumours and account for 6-13 \% of all osteosarcomas.[1]

More than $50 \%$ of craniofacial osteosarcomas arise in the jaw. Mandible is more commonly affected than maxilla[1,2] Osteosarcomas of the extragnathic craniofacial bones are rare lesions constituting fewer than $2 \%$ of all osteosarcomas and less than $0.5 \%$ of all primary bone tumors.

Extragnathic craniofacial bones are those bones of the skull excepting the jaw bones.[3] Nora et al reported a series of 21 patients with osteosarcomas of extragnathic craniofacial bones.These tumors were located over the entire calvarium. The usual involved site was occipital bone. Zygomatic arch is very rare site of involvement. ${ }^{[3,4]}$

Craniofacial osteosarcomas are classified as primary and secondary types. Primary type occurs denovo, secondary type occurs in patients with pre-existing disease like skeletal paget's disease,[3] fibrous dysplasia of bone[5] or prior regional irradiation.[3]

Patients with primary craniofacial osteosarcoma are usually present in the second and third decade.[4,6] Slight male prelection is seen.[4,6] The chief complaint of the patient is commonly a painless swelling in the particular region which is involved. [4] Sometimes the patient gives history of trauma which brings swelling to the notice. Craniofacial osteosarcomas have radiological features similar to the conventional osteosarcoma.

Computed tomography is routinely done to know the extent of bone involvement, extraosseous soft tissue extension and for precise definition of infratemporal fossa and cranial cavity.

The lesions are osteolytic, blastic or mixed variety with wide zone of transition. There is osteoid and chondroid tumor matrix mineralisation with bone destruction and soft tissue swelling. Periosteal reaction was rarely observed.[7]

Histological varieties (1) osteoblastic (2) chondroblastic (3) fibroblastic are described in the literature.[6]

Treatment is preoperative chemotherapy, en-bloc resection and post-operative chemotherapy combined with radiotherapy.[8] Extragnathic sites and failure to achieve and maintain local surgical control were reported as strong negative prognostic factors. ${ }^{[9]}$

Zygomatic arch lesions are itself relatively rare. Chondromyxoid fibroma, intraosseous hemangioma, osteoma, chondrosarcoma and ewing's sarcoma are the lesions described affecting the zygomatic arch.[10,11,12,13,14]

Osteosarcoma of zygomatic region has only been reported in three previous cases to our knowledge.[15,8,2] A study of 34 cases of osteosarcoma involving craniofascial bones [4] stated one patient with history of swelling of zygoma for over 2 years and of size $6 \mathrm{~cm}$. This can be considered the fourth case of zygomatic osteosarcoma.

Also in a large series of Mayo clinic [6] forty four cases of osteogenic sarcomas of jaws and fascial bones were included, but no tumor was reported originating in the zygomatic arch.

In another large series of review of forty three cases,[1] no single tumor arose in the zygomatic arch. 
Hence it can be concluded that our case is the fifth reported case of primary osteosarcoma of zygomatic arch.

Osteosarcoma should be considered in the differential diagnosis of lytic lesions with associated soft tissue swelling of zygomatic arch. A young patient with typical history of painless swelling of short duration preceded by history of local trivial trauma attributed to the cause of swelling should clinch the diagnosis. Radiographic features may not always be pathognomonic, the sunburst appearance may not always be seen. Histopathology is essential for the tissue diagnosis. For treatment, multimodality management is to be followed.

\section{REFERENCES:}

1. Caron AS. SI Hajdu. EW Strong. Osteogenic sarcoma of the facial and cranial bones. A review of forty-three cases. Am. J. Surg. December 1971; 122: 719-725.

2. Chindia ML. Guthua SW. Awange DO. Wakoli KA. Osteosarcoma of maxillofascial bones in Kenyans. Journal of craniomaxillofascial surgery. 1998 April ; 26 (2):98-101.

3. Nora FE.Unni KK. P DJ. Osteosarcoma of extragnathic fascial bones. Mayo Clin Proc. 1983; 58:268-272.

4. Big DS. Borges AM. Agrawal K. et al. Osteosarcoma of the craniofacial bones. A clinicopathological study. J Cranio- Maxillofacial Surg. 1991;19: 90-93.

5. Sadeghi SM. Hosseini SN. Spontaneous conversion of fibrous dysplasia into osteosarcoma. J of craniofac surg. 2011 May; 22 (3): 959-61.

6. Kragh LV. DC Dahlin. JB Erich: Osteogenic sarcoma of the jaws and facial bones. Am. J.Surg. 1958 October; 96: 496-505.

7. YY Lee. PV Tassel. C Nauert.et al. Craniofacial Osteosarcomas: Plain Film, CT, and MR findings in 46 Cases. AJNR. 1988 March-April; 9: 379-385.

8. SV Deo. NK Shukla. RK Khazanchi. GK Rath. L Chandy. MB Prakash. Multimodality management of a case of Primary osteogenic sarcoma of the Zygoma. Journal of Post Graduate Medicine 1995; 41 (1): 13-5.

9. Jasnau S. Meyer U. Potratz J.et al. Craniofacial Osteosarcoma Experience of the cooperative German-Austrian-Swiss osteosarcoma study group. Oral oncology. 2007 April; 44 (3): 286-94.

10. Bucci T.Dell G. Instabato L. Califano L. Chondromyxoid fibroma of the Zygoma: a case report. Int J Oral Maxillofac Surg. 2006 June ;35 (6): 569-71.

11. Sandra L.Moore. Jin K.Chun. Sandra A.Mitre and Peter M.Som. Intraosseous Hemangioma of the Zygoma: CT and MR Findings. AJNR Am J Neuroradiology. 2001 August; 22: 1383-1385.

12. AR Durao. I Chilvarquer. Et al. Osteoma of the Zygomatic arch and mandible: Report of two cases. Rev Porta Estomatol med dent Cir. Maxilofac 2012;53 (2): 103-107.

13. Cook HE. Chondrosarcoma arising from the zygomatic arch. J Oral Maxillofac Surg 1986 January; 44 (1): 67-9.

14. Mennie J C. Reid R. Cowie F. Hilmi O. Ewing's Sarcoma of the Zygomatic Arch Presenting in a 69 Year old: An Unusual Case Report. Case Reports in Otolaryngology. (2011).

15. HC Samant. MK Agarwal. S Gupta. D Gogoi. OP Gupta. Osteogenic sarcoma of the zygomatic region. Indian journal of otolaryngology. 1980 December; 32 (4): 127-128. 
Figure 1(A): Axial plain CT in bone window settings showing erosion of left zygomatic arch on its medial and lateral aspects with intramedullary extension (arrow) and matrix calcification.

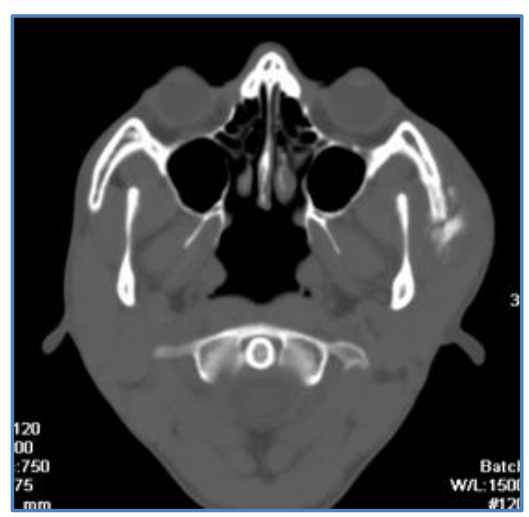

Fig. $1 \mathrm{~A}$

Figure 1 (B): Axial plain CT in soft tissue setting showing matrix calcification and soft tissue swelling.

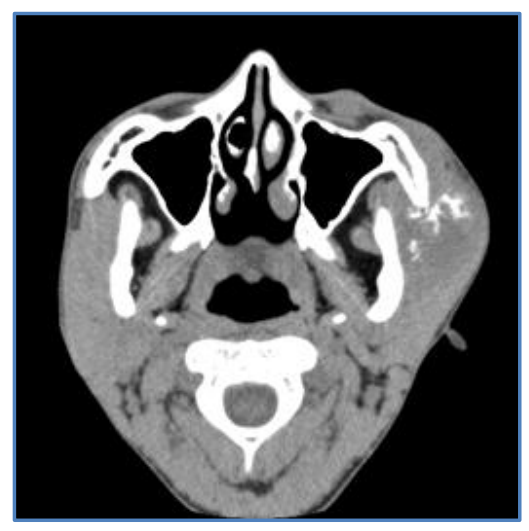

\section{Fig. 1B}

Figure 2 (A): Coronal CT in bone window setting showing cortical break (Arrow) in the zygoma.

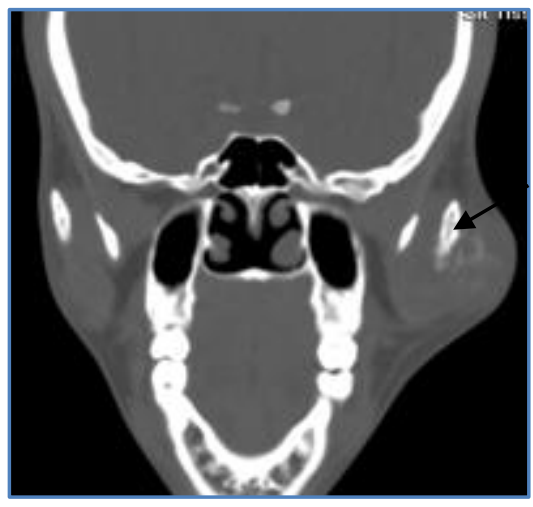

Fig. 2A 
Figure 2(B): Sagital plain CT in bone window setting showing matrix calcification and soft tissue swelling surrounding the zygomatic arch.

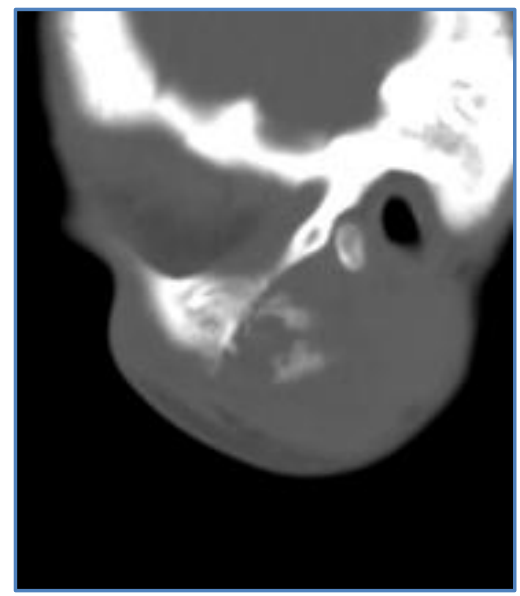

Fig. 2B

Figure 3: Tumor showing osteoid (arrow) chondroid stroma and dark staining pleomorphic tumor cells ( $\mathrm{H}$ and $\mathrm{E}, 40 \mathrm{X}$ mag).

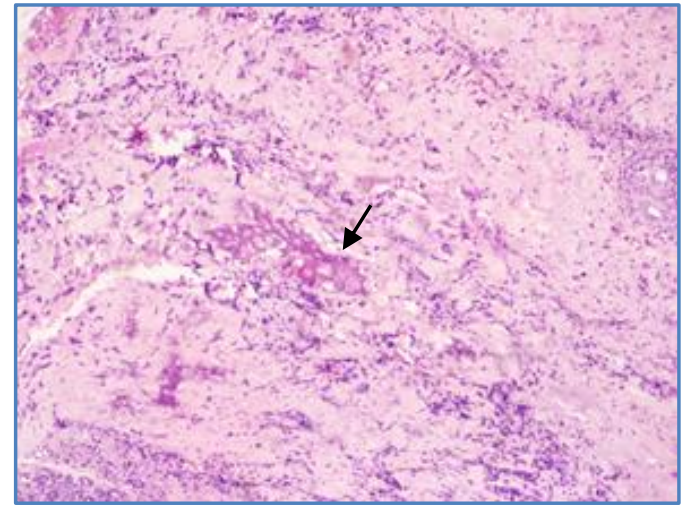

Fig. 3 


\section{CASE REPORT}

\section{AUTHORS:}

1. Vijaya Kamble

2. Kajal Mitra

3. Chetana Ratnaparkhi

4. Akshay Kapila

\section{PARTICULARS OF CONTRIBUTORS:}

1. Associate Professor, Department of Radiodiagnosis, NKP Salve Institute of Medical Sciences and Research Centre, Nagpur.

2. Professor and HOD, Department of Radiodiagnosis, NKP Salve Institute of Medical Sciences and Research Centre, Nagpur.

3. Associate Professor, Department of Radiodiagnosis, NKP Salve Institute of Medical Sciences and Research Centre, Nagpur.
4. Post Graduate Student, Department of Radiodiagnosis, NKP Salve Institute of Medical Sciences and Research Centre, Nagpur.

\section{NAME ADDRESS EMAIL ID OF THE CORRESPONDING AUTHOR:}

Dr. Vijaya Kamble,

C/o Prof. V. V. Shelkar,

Plot No. 1247, Vaishali Nagar,

Nagpur-440017.

Email: vijayakamble@hotmail.com

Date of Submission: 24/07/2014.

Date of Peer Review: 25/07/2014.

Date of Acceptance: 12/08/2014.

Date of Publishing: 18/08/2014. 